\title{
Development and Validation of Digital Storytelling Presentations through Selected Phases of Merrill's Principles of Instruction
}

\author{
Christian P. Navos, Allen Garcia, Fatima Faye Romero, Abigail San Diego, Yolanda D. Reyes \\ Bataan Peninsula State University \\ navosxchan@gmail.com,ag33470@gmail.com,Fatimafayeromero16@gmail.com, bautistaabhe@gmail.com, \\ yols1018@yahoo.com
}

\begin{abstract}
How to cite this paper: Navos CP., Garcia A, Romero FF, Diego AS and Reyes YD.. (2019). Development and Validation of Digital Storytelling Presentations through Selected Phases of Merrill's Principles of Instruction. The Educational Review, USA, 3(7), 58-66.
\end{abstract}

http://dx.doi.org/10.26855/er.2019.07.001

*Corresponding author: Christian P.Navos, Bataan Peninsula State University.

Email: navosxchan@gmail.com

\begin{abstract}
With the advent of technology and digital tools combined with adequate principles, teaching and learning literature had become more effective and efficient. Hence in this manner, the general trend in this field turned out to be digital based teaching and learning processes. Such general trend demands innovation in various areas. Among the field that requires such innovations is the storytelling which had undergone quite evolution through time. The rise of digital age had given birth to Digital Storytelling. The aim of this research is to develop and validate digital storytelling presentations through selected phases of Merrill's Principles of Instruction. The study is anchored to the fact that MPI has never been attributed to digital storytelling. Furthermore, the study discussed the underlying processes involved in the development of the material under problem-centered, activation and demonstration phases. Included in such was the selection of the stories to be used which were all taken from Philippine Literature. Moreover, the validation of the material was measured under content, instructional and technical aspect validity. The researchers included teacher experts in validating content and instructional validity while technical experts were selected to validate technical aspect validity of five materials. With a general weighted mean of 3.64 for content validity, 3.58 for instructional validity and 3.07 for technical aspect validity, the study had yielded positive and agreeable results to the MPI-based digital storytelling presentations. Finally, Cronbach validity test was conducted to ensure the reliability of the results which gave to relatively high result. Within these processes the study was able to utilize the selected phases of Merrill's Principles of Instructions in the development and validation of digital storytelling presentations.
\end{abstract}

\section{Index Terms}

digital storytelling, Merrill's Principles of Instructions, development, validation

\section{Introduction}

Stories have always been a great part of everyday life of every individual. Moreover, stories have existed long before recorded history, and the telling of stories has changed forms drastically throughout the ages. From cave painting to novels to movies, stories have always fascinated mankind Murillo et.al (2016). During the course of time the art of storytelling had undergone innovations.

Innovations of such occurred in response to the developing needs of the audience particularly the students. In retelling events that happened in a literary piece, various strategies were applied to catch the attentions of the students. This is due to the fac $\mathrm{t}$ that traditional way of telling stories imposes drawbacks and shortcomings not only to the part of the students but to story tellers themselves. As mentioned by Woodhouse (2008), traditional way of storytelling results to some disadvantages and as well as challenges. Accordingly, one of the major drawbacks of it is the time needed to implement the act of storytelling. To 
come up with a spontaneous telling of stories, one has to undergone countless rehearsals and the time consumed in presenting a story might cause boredom to students. In addition, confusion might occur in the process of restating events in a particular story. This happens when the telling of the story itself is turned in favor of the narrator itself hence it is a great challenge for the narrator to explicitly lay down the motives of the storytelling. Furthermore, simply allowing students to listen as the narrator speaks out the events might lose their interest which could lead to inability to comprehend the story well. Wasek (2013) also mentioned three disadvantages of traditional storytelling. Accordingly, first, making a good story is a challenge. Then, he also emphasized that not all trainers can read the story interestingly and lastly, sometimes participants may not get the intended learning rather confused.

To meet the needs of the present learners, different strategies and efforts are exerted by the educators. Behind every successful storytelling is the application of appropriate and adequate model. This particular notion is true specifically with regards to digital storytelling. In implementation of this tool, instructional design must be formulated beforehand. On general terms, Reiser and Dempsey (2007) provided explicit explanation of what Instructional Model is all about. Accordingly, they refer to it as systematic process that is employed to develop education and training programs in a consistent and reliable fashion.

In addition, several applications of theories have been conducted in the development of digital story telling. In his paper, Robin (2008) had also discussed about the implications and innovations of digital storytelling in classrooms learning. In his journal, he explained that digital storytelling can be a powerful educational tool for students at all ages and grade levels who are tasked with creating their own stories. Furthermore, Wang and Zhan (2010) explicitly discussed that Constructionism and Narrative Paradigm can also be used as model in designing such outputs. Constructionism practiced the ideas of learning by making while Narrative Paradigm comprises the idea of learning as a long-term process. All of these concepts were utilized in the development of digital storytelling outputs. Moreover, Morehead et al. (2007), as cited in the same paper, came up with positive results in implementing digital storytelling to classroom discussions. Furthermore, another innovation in digital storytelling was conducted at the researchers' locale. Baluyot (2017) created yet another breakthrough in digital storytelling. With the integration of ADDIE model in designing computer assisted discussion in literature, contributing another trend in digital storytelling.

Finally, with all of these innovations cited, another popular principle had emerged which has potential in the development of digital story telling. This Instructional Designs is the Merrill's Principles of Instruction. Formulated by M. David Merrill, this instructional design comprises series of interrelated phases. The framework includes a.) task- centered, b.) activation, c.) demon stration, d.) application and e.) integration phases. During these five phases, Merrill asserted that learning took place gradually.

Hence, with these relevant overviews of significant details, the study aimed to utilize Merrill's Principles of Instruction (MPI) in the development of digital story telling presentations to create another innovation. Though there are several applications of the said principle in various fields, few, if none, researches were conducted regarding the application of the principle in developing digital storytelling. Thus, the researchers used this basis in conducting the study. With that, it was generally directed to create an innovative tool in presenting literary materials. The study would also like to contribute new concepts and development with regards to creating digital story telling presentations. With the application of the aforementioned principle in developing digital storytelling outputs, the study sought to unveil innovative ways which would make analysis of stories easier.

\subsection{Statement of the Problem}

The study aimed to develop digital storytelling presentations patterned to selected phases of Merrill's First Principles of Instructions. Furthermore, it also sought to validate the MPI-based digital storytelling presentations under the selected indicators. Hence the general problem of the study is: What comprehensive analysis can be drawn from the development and validation of digital storytelling presentation through selected phases of Merrill's Principles of Instruction?

Specifically, the study sought to answer the following questions;

1. How may the development of digital storytelling presentation be described through the selected phases of Merrill's First Prin ciples of Instruction such as:

1.1 task-centered phase;

1.2 activation phase and

1.3 demonstration phase?

2. How may the of Merrill's Principles of Instruction (MPI)- based digital storytelling presentations be validated in terms of:

2.1 content validity;

2.2 instructional validity and

2.3 technical aspect validity?

3. Based on the salient results, what imperatives do the Merrill's First Principles of Instruction may constitute to literature teaching? 


\section{Methods of Research}

The descriptive-developmental research utilizes both qualitative and quantitative approach in the development and validation of digital storytelling presentations patterned using Merrill's Principles of Instruction. Generally speaking, though quantitative approach was utilized, still qualitative method was more heavily emphasized. This includes the documentation, the process and the development of MPI- based digital storytelling presentation.

In this process, the study is piloted with a research objective that has to be achieved at the end of the study. In this manner, to develop the desired material, the study utilizes the model as a principal pattern to come up with the intended output. The study comprehensively elaborated how the digital storytelling is subjected to the selected phases of Merrill's Principles of Instruction Model. These are the task- centered, activation and demonstration phases. Furthermore, validation of the output employs quantitative method. The numerical data under the selected parameters were analyzed and interpreted.

\subsection{Population and Sample of the Study}

The study encompasses selected experts and educators to validate the material. To do so, nine educators were selected to primarily validate the content of the material. Meanwhile, five Information and Communication Technology experts were selected to validate the technical aspect of the MPI-based digital storytelling presentations. The researchers utilize nonprobability sampling method, specifically the purposive sampling technique. The researchers used this technique because selected group were appropriate in validating the selected criteria.

\subsection{Research Instruments}

The study primarily documents the process which the development of digital storytelling presentation has to be undertaken. In line with this, the procedures included in each every selected phase of Merrill's Principles of Instruction are stretched and tackled.

Consequently, in order to validate the MPI-based digital story telling presentations, the researchers created their own questionnaire for pedagogical validity and this questionnaire was validated by three English teachers. While in technical validity, the researchers adopted a standardized questionnaire specifically intended for validating multimedia presentations. Venkataiah explicitly discussed the usage of these indicators. Accordingly, it is helpful to use form of checklist or a questionnaire to guide the validation process. It is good if the designer draws up list of characteristics which are developed based on indicators and learning outcomes of the material. To provide extensive scale, the validity questionnaire utilizes Likert scale. It comprises the following measurements being excellent, good, fair and poor. The measurements were quantified as numbers four (4), three (3), two (2), and one (1).

More importantly, the questionnaires used were carefully scrutinized by the validators. The indicators were selected as Venkataiah suggested to employ. However, certain modifications have to be made to the criteria under pedagogical aspect validity. With the consolidation with the teacher validators, the criteria were stated accordingly. Furthermore, the criteria under technical aspect validity yielded no irregularities thus the researchers utilized the said questionnaire.

\subsection{Data Gathering Procedure}

Primarily, the researchers developed materials through following step by step procedure in the course of developing the material. This includes the individual analysis of the implications of task-centered, activation and demonstration phases towards the development of the material. Furthermore, the process also encompasses the use of various considerations in the development of digital storytelling presentations. The questionnaire's validity was identified with the use of Cronbach Alpha. This is to ensure that the criteria should assess and validated the materials comprehensively.

Meanwhile, in the validation process, the researchers personally administered the questionnaire to the selected IT experts and educators. The researchers sought permission and administrative support from the course instructor, Leandro T. Olubia and the dean of College of Education, Dr. Lourdes S. Santos. The criteria presented in the technical aspect questionnaire were standardized. On the other hand, in the pedagogical aspect, the researchers validated their own constructed questionnaire. The validators consist of pedagogical validators and technical aspect validators. The pedagogical validators are all English Majors teachers who are knowledgeable with the story being presented and the technical validators are IT graduates and they are practicing their field of expertise. Some of the validators are from research locale (Bataan Peninsula State University) while some came from other school to assure the objectivity and avoid biases in the process of validation.

The selected validators were informed about the nature and aims of the research study. Likewise, they were assured about the objectivity of the determined indicators and criteria.

\subsection{Data Processing and Statistical Treatment}

Upon the development of the MPI-based digital storytelling presentations, the material was subjected to validation. The needed data were collected and interpreted to provide objective results. General weighted mean was used to analyze the data. The researchers subjected the results to internal consistency test using Cronbach Alpha. 


\section{Results and Discussions}

This section provides an in-depth discussion about the explanations and results regarding the development and validation of digital storytelling presentations through the selected phases of Merrill's Principles of Instruction. More explicitly, it presents answers onto how the MPI based digital storytelling presentations are developed using problem-centred, analysis and demonstration phases.

Table 1.1. Shows the general overview of the MPI-based digital storytelling Presentations

\begin{tabular}{|l|l|l|l|}
\hline Title of the Story & Author & $\begin{array}{l}\text { Time Duration of the } \\
\text { Presentation }\end{array}$ & Software used \\
\hline Dead Stars & Paz-E. Benitez & 30 minutes and 20 seconds & $\begin{array}{l}\text { Avatar Creator Microsoft } \\
\text { Powerpoint Movie Maker }\end{array}$ \\
\hline Devil in the Details & Carlos Cortes & 31 minutes and 35 seconds & $\begin{array}{l}\text { Storyboardthat.com Microsoft } \\
\text { Powerpoint Movie Maker }\end{array}$ \\
\hline Dog Eaters & Leoncio Deriada & 21 minutes and 4 seconds & Microsoft Powerpoint \\
\hline May Day Eve & Nick Joaquin & 23 minutes and 43 seconds & Pixton.com Microsoft Powerpoint \\
\hline Summer Solstice & Nick Joaquin & 24 minutes and 35 seconds & $\begin{array}{l}\text { Storyboardthat.com Microsoft } \\
\text { Powerpoint Movie Maker }\end{array}$ \\
\hline
\end{tabular}

The table shows the general features of the MPI-based digital storytelling presentations. As per described above, the presentations' range from twenty (20) to thirty (30) minutes. This is to ensure that most, if not all, of the contents of the story is covered and comprehensively discussed. Furthermore, the table also listed down the tools and software employed in the process of developing the materials. The software aided the researchers in the course of developing the material. This is very much important considering the fact that, as the name itself suggests, a digital presentation is a process of presenting stories with the use of digital tools and software.

The application of Merrill's First Principles of Instruction had contributed positive outcomes to various fields of specialization. Furthermore, the utilization of the underlying principle sets another platform for new learning.

Meanwhile, digital storytelling had been in the field of literature teaching for some quite time. With aims to provide innovative ways to understand stories better, educators set new ways to present stories is to deviate from the traditional way of storytelling. When telling stories in past was limited to either story reading and oral presentation, digital storytelling offers a much more outward opportunity for both teachers and students to learn.

Finally, when these two things were applied to various filed, none had constituted to utilization of the model based material in teaching literature. The major concepts of Merrill's First Principles of Instruction were never applied to develop a digital storytelling presentation. The flow chart below shows the procedures that were undertaken by the researchers in developing Merrill's First Principles of Instruction-based digital storytelling presentations.

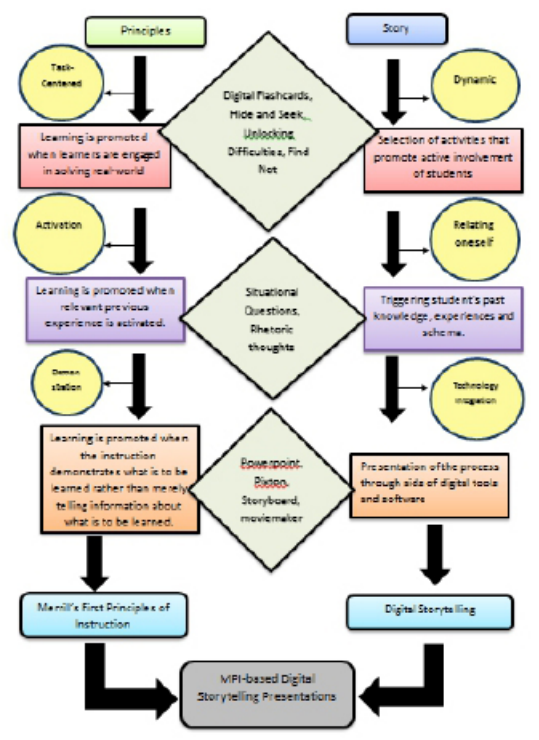




\section{How may the development of digital storytelling presentations be described through the selected phases of Merrill's Principles of Instructions such as task-centered, activation and demonstration phase?}

In the conventional way of teaching literature, teachers usually use the digital story telling as a method on uncovering the story to the students. The process is shown in the above flow chart. The left section of the chart shows the phases which the Merrill's Principles of Instruction had undertaken. In this particular study, the material or the expected output is subjected to the selected phases of Merrill's Principles of Instructions. Meanwhile, the right section of the chart deals with explicit discussion of the main considerations that have to be undertaken I developing a digital storytelling presentations.

As per presented in the chart, though selected phase on both the theoretical principles and development of digital storytelling, still various activities were deemed by the researchers to be included in the development of the material.

Hence the following discussion shall explicitly describe the process which the researchers had employed in the development of the material. The selection of instructional model to be used is a very crucial. In line with this the selection of the phases of the chosen model is equally important. How well the researchers come up with the adequate and comprehensive model depends on the purposes that this model shall constitute. In the case of the study, the aim is to develop a material that will provide another breakthrough and innovation in teaching literature.

\subsection{Task-centered Phase}

The first phase in the theoretical principles is the task centred phase. Accordingly, Learning is promoted when learners are eng aged in solving real-world problems.

Table 1.2. Shows the activities that the researchers considered in developing the material.

\begin{tabular}{|l|l|l|}
\hline Title of the Story & Author & Activites \\
\hline Dead Stars & Paz E. Benitez & Situational Question \\
\hline Devil in the Details & Carlos Cortes & Character Reference \\
\hline Dog Eaters & Leoncio Deriada & Rhetoric Questions \\
\hline May Day Eve & Nick Joaquin & Situational Question \\
\hline Summer Solstice & Nick Joaquin & Reflection \\
\hline
\end{tabular}

As the principle asserted, learning is enhanced when students know how can they solve relevant problems on their own . This process can be best observed when the teacher employs strategies and activities that catalysed both teaching and learning process respectively. In teaching process part, the way the teachers employ series of appropriate activities coul $\mathrm{d}$ mean the difference between optimum learning and just merely awareness of concepts. Students learn best when they feel they are included in the classroom set up. Consequently, in developing a digital storytelling presentation the first step that the researchers considered after choosing a story is the selection of activities that promote active involvement of students. This is done through identifying the activity.

\subsection{Activation Phase}

Following phase 1 is phase II which is triggering student's past knowledge, experiences and schema. Just like the principle described, Learning is promoted when relevant previous experience is activated.

Table 1.3. Shows the list of activities included in activation phase

\begin{tabular}{|l|l|l|}
\hline Title of the Story & Author & Selected Activity \\
\hline Dead Stars & Paz-E. Benitez & Digital Flashcards \\
\hline Devil in the Details & Carlos Cortes & Hide and Seek \\
\hline Dog Eaters & Leoncio Deriada & Q and A \\
\hline May Day Eve & Nick Joaquin & Unlocking Difficulty \\
\hline Summer Solstice & Nick Joaquin & Find Not \\
\hline
\end{tabular}

Students show interest if the way the topic introduced to them are related to their individual past experiences. This is very much important in the sense that schema of the students contributes to their learning. This is called the activation phase. In this phase students are being transferred to the story to be tackled. Consequently, this particular has to be considered hence the second step in developing the material is relating oneself. If the students were put in the shoes of the characters then it will most probably yield a better learning outcome. 
In reference to the above table, the researchers first identify what particular activity that can set the stage for learning. In the task centred phase, the students are introduced to the problems and let them solve through interactive activities. In this manner the students will gain some insights on what the presentation will deal about. These insights will be deeply triggered through asking situational questions and such. Hence this consideration is very sensitive in the séance that, personally, the researchers tend to align the questions to the general idea of the story.

\subsection{Demonstration Phase}

And lastly on the third phase, it shows story through an innovative presentation. The idea is that to deviate from usual presentation of the stories. Just like what the principle explicitly discussed,

Learning is promoted when the instruction demonstrates what is to be learned rather than merely telling information about what is to be learned.

In the traditional storytelling, the set up can be described just like the old school narration of stories. It is like what the Greeks had practiced wherein the audience will circle around as they passively listen to what the narrator is saying to the. In a classroom setup, the variations of this tradition had been practiced. Oftentimes, teachers will allow the students to read some parts of the passage and then expound the ideas.

More importantly, upon undergoing to the prior two phases, it is pretty much safe to assume that the students are now expected to be prepared with the actual presentation of the story. This is where everything gets in order. The researchers incorporated the activities include in the prior phases and then relate the extracted ideas to the general theme of the story. Hence the demonstration will greatly depend upon how the task centred and activation phases were implemented. Likewise, the activation phase of the presentation is dependent on the nature of the task or problem presented in the initial phases.

In creating a much interactive way of demonstrating stories, the researchers incorporated the above-mentioned principles of Merrill's instructional model. To accomplish this, the aid of technological tools is very much crucial. Figure below shows the individual captions of the development of the material.

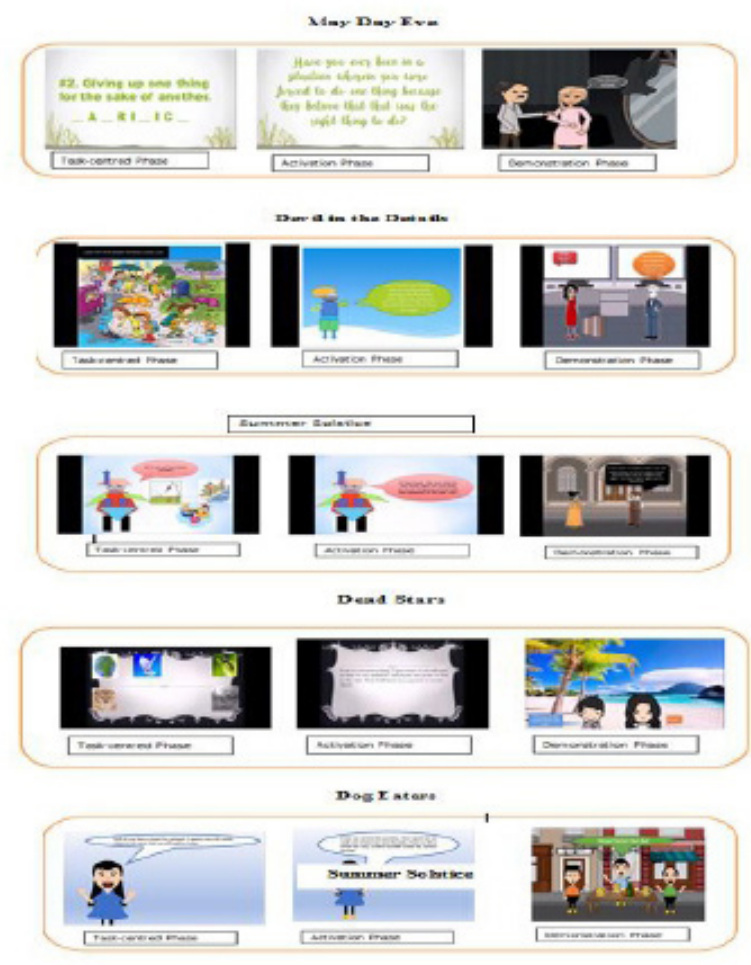

Through following the step by step procedures presented in the study, the material has been developed and the underlying principles of the selected model. The following table and representations shows the validity results of the material.

2. How may the Merrill's Principles of Instructions (MPI)-based digital storytelling presentations be validated in terms of content, instructional and technical aspect validity? 
Table 1.4. Shows the general weighted mean scores of the materials under pedagogical (content and instructional validity) aspect

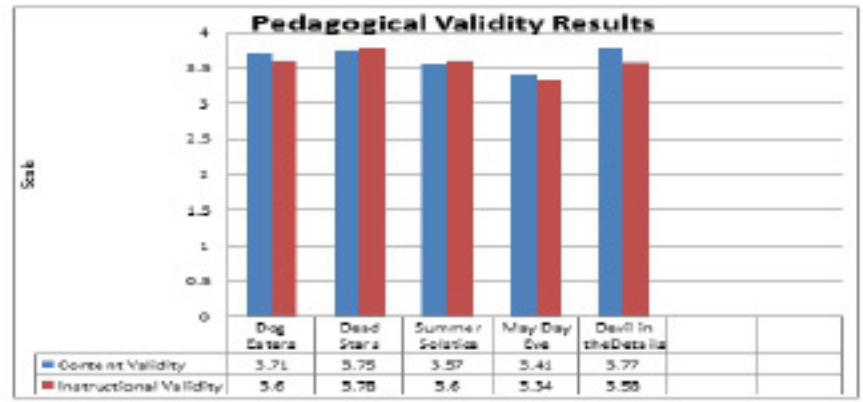

The table shows level of validity of the MPI-based digital storytelling in terms of pedagogical aspect which covers content validity and instructional validity. The result from the questionnaire was solved using the mean to determine how valid the designed instructional material.

The result indicated that the digital storytelling that the researchers have made got a positive feedback from the validators. Dog Eaters got 3.71 in terms of content validity and 3.6 when it comes in instructional validity. While the Dead Stars acquired 3.75 in content validity and 3.78 in instructional validity, summer Solstice got 3.57 in content validity while its instructional validity is 3.6. May Day Eve on the other hand attained 3.41 in content validity and 3.34 in instructional validity. Lastly, the Devil in the Details was 3.77 in content validity and 3.58 in instructional validity.

Table 1.5. Shows the general weighted mean scores of the materials under technical validity aspect

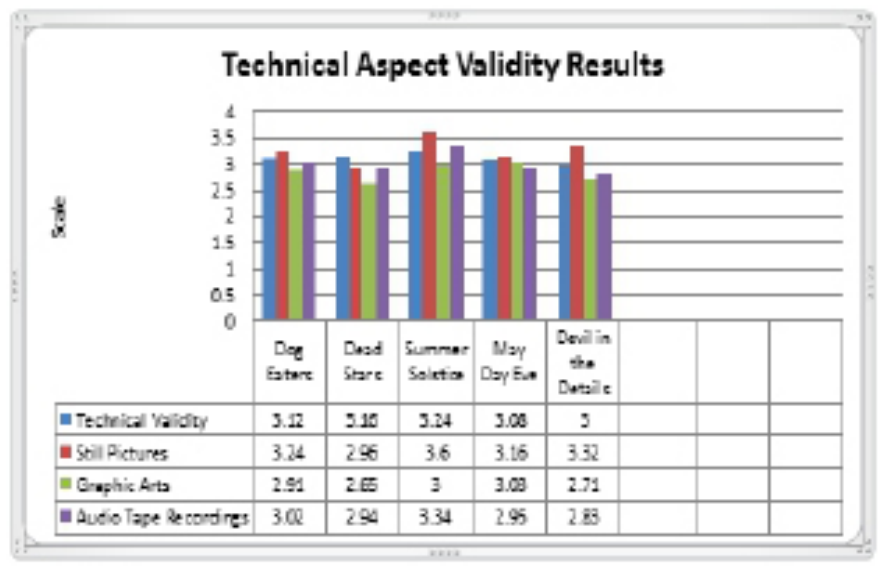

The table above shows level of validity of the MPI-based digital storytelling in terms of technical aspects which include still pictures, graphic arts and audio tape recordings. The result from the questionnaire was solved using the mean to determine how valid the designed instructional material. The result indicated that the digital storytelling that the researcher has made got a posi tive feedback from the validators.

Likert Scale was used as the basis in determining the validity of the material where 3.28 to 4.00 is very good, 2.52-3.27 is good, 1.76-2.51 is bad and 1.00-1.75 is very bad.

First, the Dog Eaters got 3.12 in technical validity, 3.24 in still pictures, 2.91 in graphic arts and 3.02 in audio tape recordings. Second, Dead Stars resulted 3.16 in technical validity, 2.96 in still pictures, 2.65 in graphic arts and 2.94 in audio tape recordings. Third, Summer Solstice got 3.24 in technical validity, 3.6 in still pictures, 3 in graphic arts and 3.34 in audio tape recordings. Fourth, May Day eve acquired 3.08 in technical validity, 3.16 in still pictures, 3.03 in graphic arts and 2.95 in audio tape recordings. Lastly, Devil in the Details got 3 in technical validity, 3.32 in still pictures, 2.71 in graphic arts and 2.83 in audio tape recordings.

To cut it short, the MPI-based digital storytelling that the researchers have designed is valid in terms its technical aspect since no score falls lower than 2.51 or bad.

It can be seen with the figures shown using Likert Scale as the basis where:

3.28 to 4.00 is very good, 2.52-3.27 is good, 1.76-2.51 is bad and 1.00-1.75 is very bad. 


\begin{tabular}{ll}
\hline Scale/Range & Description \\
\hline $1.00-1.75$ & Strongly Disagree \\
$1.76-2.51$ & Disagree \\
$2.52-3.27$ & Agree \\
$3.28-4.00$ & Strongly Agree \\
\hline
\end{tabular}

The data above clearly shows that the MPI-based digital storytelling presentation is valid considering its pedagogical aspects. The above table shows the general overview of the Cronbach's Alpha results. As per shown in the above table, the results of the Cronbach analysis yielded acceptable range near 0.6. Though some areas were noted below the accepted range still, the general validity tests exceeded the expectations.

\begin{tabular}{|c|c|c|c|c|}
\hline & 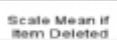 & $\begin{array}{l}\text { Beale } \\
\text { variance at } \\
\text { tram Deeieted }\end{array}$ & $\begin{array}{l}\text { Competesed } \\
\text { 15om-Total }\end{array}$ & $\begin{array}{l}\text { Cronbachs } \\
\text { Alphaithom } \\
\text { Deteted }\end{array}$ \\
\hline TECHNICALSE & 93.6000 & 12.300 & 257 & \\
\hline CONTENTSS & 93.5600 & 13.488 & & \\
\hline INSTRUCTIONALSS & 93.5000 & 13035 & oos & \\
\hline $\begin{array}{l}\text { TECHALCALDS } \\
\text { CONTERTOS }\end{array}$ & 93.9400 & 13.000 & $\begin{array}{r}-243 \\
031\end{array}$ & .653 \\
\hline $\begin{array}{l}\text { CONTENTDS } \\
\text { INSTRUCTOHULDS }\end{array}$ & 93.3000 & 12440 & 319 & $\begin{array}{l}631 \\
606\end{array}$ \\
\hline TECHRECALMODE & 940200 & 12212 & 221 & 613 \\
\hline CONTENTMDE & 93.7400 & 12.423 & 101 & \\
\hline INETRUCTONALMDE & 93.7400 & 1.973 & 294 & \\
\hline TECHAECALOD & 94.0200 & 11.652 & 600 & \\
\hline CONTENTDD & & 12330 & $A 7$ & .599 \\
\hline 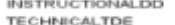 & & 12852 & 039 & 626 \\
\hline $\begin{array}{l}\text { TECHAHCALTDE } \\
\text { CONTENTTDE }\end{array}$ & $\begin{array}{l}93.9600 \\
93.3 \times 00\end{array}$ & $\begin{array}{r}11.002 \\
13517\end{array}$ & $\begin{array}{r}490 \\
-141\end{array}$ & .574 \\
\hline RUCTIONALTER TOE & 93.4200 & $\begin{array}{l}13.617 \\
14.572\end{array}$ & 年 & $\begin{array}{l}.635 \\
.665\end{array}$ \\
\hline & & & 324 & \\
\hline BSGRAPHEC & 94.2600 & 12568 & 285 & \\
\hline & 93.6000 & 12.428 & 106 & .620 \\
\hline DSFICTURES & $94: 10$ & & & \\
\hline DSORAPHICS & 94.5600 & 12.752 & 736 & .608 \\
\hline CTURES & $\begin{array}{l}94.1400 \\
970400\end{array}$ & $\begin{array}{l}14.468 \\
11.028\end{array}$ & 46 & \\
\hline $\begin{array}{l}\text { MDEFICTURES } \\
\text { MDEORACHICS }\end{array}$ & & & $\begin{array}{l}0.00 \\
267\end{array}$ & 503 \\
\hline & $\begin{array}{l}94,27000 \\
94,000\end{array}$ & $\begin{array}{l}126772 \\
12560\end{array}$ & ${ }_{200}^{267}$ & .612 \\
\hline URES & & 1.652 & 617 & \\
\hline AAHICS & 1.5000 & 12072 & 412 & \\
\hline & 94.1600 & 11.772 & 458 & -5es \\
\hline & 93.8200 & 12.332 & 313 & .005 \\
\hline $\begin{array}{l}\text { TDEGRAPHICS } \\
\text { TDEATR }\end{array}$ & 94.0200 & 11.072 & .650 & 503 \\
\hline
\end{tabular}

Generally speaking, the overall presentations that the researchers have designed is valid in both Technical and Pedagogical aspect based on the results acquired. This instructional material can be now used in teaching and learning process since it was validated by the experts.

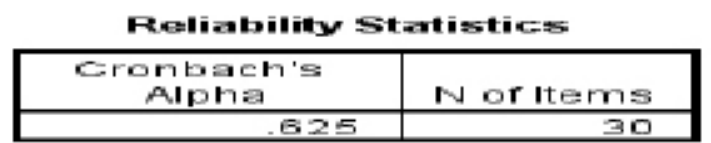

Hence with these results the study is able to come up with the imperatives to literature teaching.

\section{Based on the salient results, what imperatives do the Merrill's First Principles of Instruction may constitute to literature teaching?}

The increasing demands of students' needs in knowledge particularly in understanding literary pieces had resulted to the development and implementation of strategies which aims to cater these needs. Furthermore, when traditional presentation of the stories had contributed to the capability of the students to sustain interest and understanding towards various literary pieces, still the above tabulated data had revealed positive outcomes regarding the utilization of digital storytelling presentations in teaching literature. Hence, the following imperatives would suggest how these presentations may constitute in teaching literature to students.

\section{- Digital storytelling presentation is a new platform for students to understand literary pieces better.}

The content of the digital storytelling presentation is specifically derived from the story itself. At one look, one would most probably think that there is no difference between presenting the events in the story digitally and narrating those orally. But the deviation can be observed on how the contents are operated to target the needs of the students. When stories are told orally, the tendency is that students might think that the story is actually long thus making them unable to sustain interest all throughout but using digital storytelling presentations the student's motivation to understand the topic is increased due to the fact the concepts, ideas and themes are not only concretized but also presented in much more engaging way. Finally, the used 
of Merrill's Principles of Instruction constituted to the alignment and order of the events presented in the story.

\section{- Organization of thoughts is well established in a digital storytelling presentation.}

Spontaneous narration of the events in the story orally is next to impossible considering the fact that no matter how much the narrator rehearsed still the odds of omission of details is deliberately high. Often times, to satisfy the personal convenience of the narrator, he/she tends to compromise some details in the story thus hindering the students' understanding of the piece itself whereas with the use of digital storytelling presentation, the topic can be presented with precision with the use of digital tools which can make the preparation of the material easier. Moreover, the uses of the model deliberately allow the presentation to have systematic order.

\section{- Digital storytelling presentation is an innovative way in engaging our students.}

Everyone gets bored every time the narrator simply read the content provided by the book. The addition of facial expressions and gestures by the narrator may engage the students but not in a way a digital storytelling presentations can do. The above cited numerical data had shown how appealing a digital storytelling presentation can be to students. The students are also engaged more if the material is new to them. With the use of digital tools, discussion of lengthy stories can now become more exciting with the use of this kind of presentation. Furthermore, the instructional model employed serves as a breakthrough in the field of digital storytelling. When the model has been applied to various fields, MPI provided an entirely transformative application to literature teaching.

\section{- The usefulness of digital storytelling presentations can make teaching literature more efficient and effective.}

Digital storytelling presentation is very much convenient for both teachers and students. Preparing traditional materials in discussing events in a literary piece is surely a hard thing even for experienced teachers. The amount of time needed to prepare a stage for another story is longer compare with the development of digital storytelling presentations Furthermore, the vast options to be choose from in creating presentation being from selecting characters and to adding some attachments categorized digital storytelling presentations as an efficient material in teaching literature. These particular assertions can be observed in the data obtained from the respondents. A $21^{\text {th }}$ century student must be provided with a material that perfectly suits their $21^{\text {st }}$ century learning needs. Finally, the phases of the material included in the Merrill's Principles of Instructions are all intended to navigate students to a much more innovative way of learning literary pieces. With the use of step by step procedures, which the material had conducted, students are gradually guided through a better absorption of learning process which is missing with the usual or old ways of storytelling presentations.

\section{REFERENCES}

[1] Gus Murillo, R. K. (2015). The Big Fish Experience: Create Memorable Presentations That Reel in Your Audience. New York.

[2] J. Woodhouse (2008). Storytelling: A Telling Approach in Healthcare Education

[3] Wasek, Dewan Abu. (2013). The Advantages and Disadvantages of Story Telling in a Training of Trainer's (TOT) course

[4] Robert A. Reiser, J. V. (2007). TRENDS AND ISSUES IN INSTRUCTIONAL DESIGN AND TECHNOLOGY. Boston S4Carlisle Publishing Services.

[5] Robin, B. (2008). The Educational Uses of Digital Storytelling. University of Houston.

[6] Merrill, (2002). First Principles of Instructions. ETR and D, Vol.50 No.3. pp 40-59

[7] Robin (2008). Digital Storytelling: A Powerful Technology Tool for the $21^{\text {st }}$ Century Classroom. Theory Into Practice. The Ohio State University

[8] Wang and Zhan (2010). Enhancing Teaching and Learning with Digital Storytelling. International Journal of Information and Communication Technology Education. IGI Publishing Hershey. USA

[9] Baluyot,M.et al. (2017). Assessment of Technology based Instructional Material in Teaching Literature. Bataan Peninsula State University.

[10] Merrill, M. D. (2002). "First principles of instruction." Educational Technology Research and Development 50(3), 43-59.

[11] Hancock B. (2007), Windridge K., and Ockleford E. An Introduction to Qualitative Research. The NIHR RDS EM / YH

[12] Venkataiah, N. (2008). Educational Technology, APH Publishing Corporation 